\title{
HISTÓRIA DA LEITURA: PROFESSORES LEITORES, POLÍTICAS DE CIRCULAÇÃO DO LIVRO E AS REVERBERAÇÕES NA DOCÊNCIA
}

\author{
HISTORIA DE LA LECTURA: PROFESORES LECTORES, POLÍTICAS DE \\ CIRCULACIÓN DEL LIBRO Y LAS REVERBERACIONES EN LA DOCENCIA
}

\author{
HISTORY OF READING: PROFESSORES LEITORES, BOOK CIRCULATION \\ POLICIES AND REVERBERATIONS IN TEACHING
}

\author{
Marta Rochelly RIBEIRO GONDINHO ${ }^{1}$ \\ Luisa Xavier de OLIVEIRA ${ }^{2}$ \\ Caio VELOSO ${ }^{3}$
}

RESUMO: O presente artigo perscruta os reflexos dos estudos preconizados por Roger Chartier nas investigações acerca da história da leitura. Se a história da leitura é a história dos seus leitores, investigar professores e seus modos de fabricação de um universo leitor pode nos levar a uma compreensão mais elaborada de como os professores leitores constroem uma ambiência de leitura em suas práticas pedagógicas cotidianas. Este estudo tem como objetivo analisar a relação entre o capital cultural e a formação leitora de professores da rede pública em Teresina-PI, mais especificamente na Escola Municipal Professor Valdemar Sandes. Nesse sentido investigou-se, a partir de fragmentos da história de vida relatada pelos professores pesquisados, seus itinerários de formação leitora e seus desdobramentos para a vida pessoal e profissional dos sujeitos. Para tanto, utilizou-se a metodologia da história oral, fazendo a construção de dados a partir de entrevistas narrativas nas quais foi enfocada a questão da leitura como prática cultural dos referidos professores. Na medida em que se foi situando teoricamente as elucidações conceituais, estudou-se os fragmentos destas narrativas e a posteriori foi feita uma análise dos ditos dos informantes. No primeiro momento, introduziu-se uma discussão sobre a leitura e a construção da legitimidade desta como uma prática cultural simbólica inferindo sobre as políticas de circulação do livro e, posteriormente, dialogou-se com os estudos sobre formação docente, habitus e capital cultural de professores através das narrativas biográficas. Estas discussões estão fundamentadas nas contribuições da história cultural (CHARTIER,1999) e na teoria das estruturas sociais, ou praxiologia, proposta pelo sociólogo francês Pierre Bourdieu, centrando-se principalmente nos conceitos de capital cultural (BOURDIEU, 1975; 1989; 1990; 1998; 1999; 2007). Desta forma, concluise que o capital cultural é todo recurso ou poder que se manifesta em uma atividade social referindo-se a um capital simbólico que no tocante à formação de professores e às práticas leitoras apresenta um itinerário plural. Também se verificou que os sujeitos apresentam semelhanças em seus percursos de vida e formação, pois estão inseridos nas classes menos

\footnotetext{
${ }^{1}$ Universidade Federal do Piauí (UFPI), Teresina - PI - Brasil. Professora Adjunta do Departamento Métodos e Técnicas de Ensino - DMTE. Doutorado em Educação (UFRJ). ORCID: https://orcid.org/0000-0001-9726-2880. E-mail: martarochelly81@hotmail.com

${ }^{2}$ Universidade Federal do Piauí (UFPI), Teresina - PI - Brasil. Professora Adjunta do Departamento Métodos e Técnicas de Ensino - DMTE. Doutorado em Educação (UFRJ). ORCID: https://orcid.org/0000-0003-0782-4793. E-mail: luisaxavier77@yahoo.com.br

3 Universidade Federal do Piauí (UFPI), Teresina - PI - Brasil. Doutorando em Educação. ORCID: https://orcid.org/0000-0002-0397-0796. E-mail: caio.veloso@ifma.edu.br
} 
favorecidas da sociedade e estes também apresentam aspectos dissonantes caracterizados pelos seus modos de interagir com a cultura.

PALAVRAS-CHAVE: Formação de professores. Leitura. Capital cultural.

RESUMEN: Este artículo examina los efectos de los estudios realizados por Roger Chartier en las investigaciones acerca de la historia de la lectura. Si la historia de la lectura es la historia de sus lectores, investigar profesores y sus modos de fabricación de un universo lector nos puede llevar a una comprensión más elaborada de cómo los profesores lectores construyen una ambientación de lectura en sus prácticas pedagógicas cotidianas. Este estudio tiene por objeto analizar la relación entre el capital cultural y la formación lectora del profesorado de la red pública en Teresina-PI, más bien en la Escuela Municipal Professor Valdemar Sandes. En este sentido, se investigó a partir de fragmentos de la historia de vida relatada por los profesores participantes de la investigación, sus itinerarios de formación lectora y sus repercusiones en la vida personal y profesional de los sujetos. Para ello, se utilizó la metodología de la historia oral, haciendo la construcción de datos a partir de entrevistas narrativas en las cuales se enfocó la cuestión de la lectura como práctica cultural de dichos profesores. A la medida que se situó teóricamente las elucidaciones conceptuales, se estudió los fragmentos de estas narrativas y a posteriori se realizó un análisis de las palabras de los informantes. En el primer momento, se introdujo una discusión sobre la lectura y la construcción de la legitimidad como una práctica cultural simbólica infiriendo sobre las politicas de circulación del libro y, posteriormente, se dialogó con los estudios sobre formación docente, habitus y capital cultural del profesorado a través de las narrativas biográficas. Estas discusiones están basadas en las contribuciones de la historia cultural (CHARTIER,1999) y en la teoría de las estructuras sociales, o praxiología, propuesta por el sociólogo francés Pierre Bordieu, se centrando principalmente en los conceptos de capital cultural (BOURDIEU, 1975; 1989; 1990; 1998; 1999; 2007). De esta forma, se concluye que el capital cultural es todo recurso o poder que se manifiesta en una actividad social, refiriéndose a un capital simbólico en lo que respecta a la formación del profesorado y a las prácticas lectoras, presenta un recorrido plural. También se verificó que los sujetos presentan semejanzas en sus trayectorias de vida y formación, ya que están insertados en las clases menos favorecidas de la sociedad y estos también presentan aspectos disonantes caracterizados por sus modos de interactuar con la cultura.

PALABRAS CLAVE: Formación del profesorado. Lectura Capital cultural.

ABSTRACT: This paper examines the reflections of Roger Chartier's studies on the history of reading. If the story of reading is the story of its readers, investigating teachers and their ways of making a reading universe can lead us to a more elaborate understanding of how reading teachers build a reading environment in their daily pedagogical practices. This study aims to analyze the relationship between the cultural capital and the reading education of public school teachers in Teresina-PI, more specifically in the Municipal School Professor Valdemar Sandes. In this regard, fragments of the life history reported by the researched teachers were investigated, as well as their itineraries of reading education and their unfolding into the personal and professional lives of the subjects. Therefore, the methodology of oral history was used, making the construction of data from narrative interviews in which the question of reading was focused as a cultural practice of these teachers. As the conceptual elucidations were theoretically located, the fragments of these narratives were studied and a 
posteriori an analysis of the sayings of the informants was made. In the first moment, a discussion on reading and the construction of its legitimacy as a symbolic cultural practice was introduced, inferring about the policies of circulation of the book and, later, dialogue was held with the studies on teacher training, habitus and cultural capital of teachers through biographical narratives. These discussions are based on the contributions of cultural history (CHARTIER, 1999) and the theory of social structures, or praxeology, proposed by the French sociologist Pierre Bourdieu, focusing mainly on the concepts of cultural capital (BOURDIEU, 1975; 1989; 1990; 1998; 1999; 2007). Thus, it is concluded that cultural capital is every resource or power that manifests itself in a social activity referring to a symbolic capital that in relation to teacher training and reading practices presents a plural itinerary. It was also verified that the subjects present similarities in their life and formation paths, since they are inserted in the less favored classes of society and these also present dissonant aspects characterized by their ways of interacting with culture.

KEYWORDS: Teachers' formation. Reading. Cultural Capital.

\section{Introdução}

Em meio a uma sociedade letrada, marcada pelas imbricações de uma cultura grafocêntrica, pelas sombras das experiências com as letras, pelas palavras, pelas expressões de uma comunicação registrada e pelos suportes multifacetados da escrita é que se depara introdutoriamente com um dos maiores problemas identificados na realidade escolar brasileira: a leitura. Desse modo, a questão da leitura se situa numa trama histórica, política, social e cultural.

Com os discursos de democratização da escola que marcaram especialmente as décadas de 1980 e 1990 no Brasil, tem-se direcionado nas políticas educacionais ações para o problema de aprendizagem da leitura e da escrita. Este problema é apresentado como o grande gerador das desigualdades na escola, uma vez que é apontado como a explicação para o fracasso escolar.

Diante disso, a questão da leitura na atualidade vem se desnaturalizando, quebrando a barreira do supostamente natural e se apresentando como um complexo emaranhado de ditos que ganham legitimidade enquanto prática social. As estatísticas oficiais apontam o problema da leitura como uma causa social, uma vez que é nas camadas populares, em realidade escolar pública, que é mais fortemente indicada as disparidades entre o universo leitor e não-leitor.

A leitura, enquanto prática cultural criadora, redesenha a educação escolar, protagonizando um processo no qual se recriam inúmeros outros atores sociais que capturam a cena e reinventam o que se apresenta como principal. Todavia, vários estudos, em diferentes 
áreas do conhecimento, têm posto em discussão a formação leitora tanto sob a ótica docente, quanto discente.

Pensar a educação escolar e seus atores sociais em suas múltiplas faces é evidenciar os questionamentos que se intensificam ao longo de décadas. Vive-se um momento marcado por rearranjos que investigam releituras e percepções, como é evidente o consenso de cientistas de uma determinada época a respeito do que são as questões significativas e quais as explicações e teorias aceitáveis, chamando assim, a atenção para o tipo de leitura que fazemos das realidades sociais (ALBUQUERQUE, 1993). Nesse sentido, propõem-se os seguintes questionamentos: que tipo de discursos são legitimados? Que tipos de práticas pedagógicas autoritárias foram convencionadas na realidade escolar? Como as políticas públicas de circulação de livros influenciam na fabricação do leitor? Questões dessa natureza impulsionam o efervescer das buscas explicativas. Pesquisar é um ponto de partida para pensar a realidade social.

A construção do norteamento desta pesquisa partiu do pressuposto de que existe um discurso legítimo sobre leitura e sua aquisição enquanto prática cultural na escola, bem como pela necessidade de compreender a constituição do habitus leitor e as implicações do capital cultural na formação de professores. Sendo assim, qual discurso legitima as práticas de leitura na escola? Como pensar sob esta ótica a formação de professores? Que relação pode ser estabelecida entre o capital cultural e a formação leitora de professores?

As pesquisas na área da leitura, em crescimento no Brasil, têm suscitado e promovido amplo debate teórico sobre o contexto educacional e abraçado o desafio de envolver qualitativamente os sujeitos no pensar criticamente suas realidades e cotidianos.

Contextualmente, a história da leitura é envolvida de peculiaridades sociais, culturais, históricas e pedagógicas. A intenção é atravessada pela episteme da curiosidade, pela sedução pelo tema e pela busca de partilhar conhecimentos sobre o mundo da leitura e sobre a leitura do mundo numa conexão que vai do itinerário da vida social aos bastidores escolares. Para isso foram entrevistados professores da escola supracitada amparados sob a égide de uma pesquisa qualitativa, embasados nos procedimentos da história oral, tendo a entrevista narrativa biográfica como método de coleta de dados.

Compreender a formação leitora e as artes de fazer cotidianas dos professores nos permitirá adentrar num palco plural onde contracenam e se aproximam em relação à leitura percursos de vida, tecidos pelas experiências, com as marcas da objetividade e da subjetividade. 
História da leitura: professores leitores, políticas de circulação do livro e as reverberações na docência enquanto tema desta pesquisa, tratou de uma análise das práticas culturais e da formação leitora de professores da rede pública municipal de Teresina-Piauí.

Esta pesquisa se inscreve no vasto campo de estudo da formação de professores. Para tanto, foi situada no campo teórico da abordagem sociológica de Pierre Bourdieu (1974,1982); Jean-Claude Passeron (1974) que entendem a educação como reprodutora da estrutura da sociedade, isto é, de suas desigualdades sociais; Bernard Lahire (2002); Roger Chartier (1999) que estuda a leitura e sua historicidade como uma prática cultural; e a discussão do conceito de estratégia em Michel de Certeau (1996) e Antonio Nóvoa (2002) que estuda a formação de professores e suas histórias de vida.

Por tanto, aprofundar tais fundamentos pela pesquisa, mais especificamente, significa tomar as trajetórias como foco das investigações, deslocar o olhar para a leitura e estabelecer uma relação que pode ser de determinação ou não, pelo percurso de formação de professores, por suas biografias e suas práticas cotidianas de leitura, uma vez que entre a formação e as práticas existem as estratégias postas em ação. Essas estratégias podem ser postas em ação pela relação dos professores e a experiência acadêmica inicial, ou a própria formação continuada.

Analisar o itinerário da formação leitora de professores da rede pública municipal de ensino de Teresina-Piaú́ constituiu o objetivo geral desta pesquisa que se desmembrou especificamente em analisar a relação entre o capital cultural e a formação leitora de professores da Escola Municipal Professor Valdemar Sandes e identificar na biografia dos professores pesquisados os itinerários da leitura e seus desdobramentos.

Acredita-se, desse modo, que esta pesquisa aponta relevantes possibilidades de estudo que podem instigar a análise da cultura letrada no universo escolar pelo habitus docente e pela prática pedagógica do professor.

\section{Leitura: o Capital Cultural e a Formação de Professores}

No Brasil, a questão da formação de leitores se constitui como uma dívida histórica presente nos discursos oficiais republicanos e nas propostas de políticas públicas como uma prática necessária ao exercício da democracia. Esta questão parece denunciar, ao mesmo tempo, tanto uma realidade não-leitora, como evidencia uma suposta preocupação política com a formação leitora. 
Considerando os mecanismos de reprodução da desigualdade social denunciados por Bourdieu e Passeron na década de 1970, entenderemos contextualmente o advento de uma sociedade grafocêntrica, pautada na experiência com as letras, típica da civilização ocidental, como um advento excludente desde sua gênese.

A História da leitura permite pensar a sua ação nas continuidades e mudanças do tempo. Os modos de conhecer a leitura promovem uma consciência crítica para que a partir dos problemas do presente possamos conhecer, com pontos de vista ancorados num estudo rigoroso, o passado.

Teceremos agora algumas elucidações sobre a leitura no Brasil, país de uma grande dimensão geográfica, com raízes em uma sociedade escravocrata e excludente onde a questão da leitura é, sobretudo, política. As políticas públicas de educação no Brasil acerca da leitura estão alicerçadas num território de desigualdade que vai desde o mercado de material impresso até as políticas de incentivo a leitura.

No Brasil a sistematização do espaço escolar com bases axiológicas de conhecimento, caráter ideológico, ordenamento de valores, esteve intrinsecamente relacionada às atribuições de ensinar, e especificamente ensinar a ler.

Uma vez contextualizada historicamente a leitura, evidenciamos que as práticas culturais da leitura estão inscritas e datadas no tempo, revelando que a leitura é uma construção social imersa numa relação de sentido de ação cotidiana e das "artes do fazer" de cada agente social, circunscrita tanto num cenário coletivo como individual.

Nessa perspectiva, Bernard Lahire (2002) explora o conceito de ator plural que, uma vez colocado, simultânea ou sucessivamente, dentro de uma pluralidade de mundos sociais não homogêneos, ou até contraditórios, constituiria um estoque de esquemas de ações ou hábitos não homogêneos, não unificados e consequentemente, teria práticas heterogêneas que variariam de acordo com o contexto social. "Um ator plural é produto da experiência de socialização em contextos sociais múltiplos e heterogêneos" (LAHIRE, 2002, p. 31). Assim, cada ator vai constituindo o seu repertório de esquemas de ação (de hábito), que Lahire chama de síntese de experiências sociais incorporadas ao longo da socialização.

Para Lahire (2002), a prática é sempre os pontos de encontro das experiências passadas individuais que foram incorporadas sob a forma de esquemas de ação, de hábitos, de maneiras de ver, sentir, de dizer e de fazer e de uma situação social presente.

Assim, "O sistema de ensino é um dos mecanismos pelos quais as estruturas sociais são perpetuadas" (BOURDIEU, 2002, p. 14). Esta percepção introduz de forma conceitual a análise do impacto da origem social e das experiências culturais na ação dos atores sociais 
presentes no cotidiano escolar. A escola se constitui como espaço de reprodução das relações sociais. Existe uma correspondência constitutiva na identidade e na prática pedagógica do professor, entre o seu contexto social e cultural, seus significados, motivações, expressões e gostos.

Para tal compreensão entra o conceito de habitus, ou o "sistema de disposições duráveis que exprimem sob a forma de preferência sistemática, as necessidades objetivas das quais ele é o produto" (ORTIZ, 1983, p. 82). Nesta perspectiva, a prática pedagógica dos professores, tecendo um diálogo educacional, diz muito sobre a prática do conceito de Bourdieu. Estas práticas envolvem as práticas dialógicas, evidenciando a marca do contexto e da cultura, sendo então asseguradas entre as ações do individuo, já que

as práticas que o habitus produz (enquanto princípio gerado de estratégias que permitem fazer face as situações imprevisíveis e sem cessar renovadas) são determinadas pela antecipação implícita de suas consequências, isto é, pelas condições passadas da produção de seu principio de produção de modo que elas tendem as reproduzir as estruturas objetivas das quais elas são, em última análise o produto (BOURDIEU, 1994, p. 61).

Assim, compreende-se a educação como reprodutora da estrutura da sociedade e consequentemente das desigualdades sociais. O trabalho escolar sob esta ótica visa confirmar os habitus pré-existentes ou substituir este por outro mais condizente com arbitrário cultural. O habitus é então, produto das condições materiais de existência, característicos de uma condição de classe que por sua vez, é definida pela posição do agente no espaço social. O habitus produz práticas que, para serem explicadas, necessitam que coloquemos em relação

a estrutura objetiva que define as condições sociais de produção do habitus (que engendrou essas práticas) com as condições do exercício desse habitus, isto é, com a conjuntura que salvo transformação radical representam um estado particular dessa estrutura (BOURDIEU, 1964, p. 65).

O processo de leitura para Bourdieu se estabelece em uma compreensão de disputa simbólica pelas nomeações legítimas de poder e valor do discurso. Para esse autor, a leitura tem a necessidade de ser compreendida não apenas como competência linguística, mas como um capital simbólico no sentido que a linguagem deve ser compreendida como práxis, portanto, necessariamente referida às situações que lhe conferem sentido e que condicionam a sua expressão. Na medida em que todo ato de produção cultural implica na afirmação de sua pretensão à legitimidade cultural, isto é, a luta pelo monopólio da manipulação legítima de uma determinada espécie de bens simbólicos, se estabelece o conflito no processo de comunicação, conflito este que decorre da existência de princípios diferenciados de 
legitimação que estão em jogo. A disputa fundamental é, pois, referente ao poder simbólico de estabelecimento das distinções.

Pensar sobre a problemática da leitura na atualidade é um exercício, um desafio que ínsita farejar pela história. A leitura é atualmente muito discutida nos bastidores escolares, há quem a aponte como o indicativo do fracasso escolar, ou como uma prática cultural necessária para o desenvolvimento da autonomia, ou como elemento imprescindível de uma aprendizagem voltada para o exercício da cidadania e até quem diga que não vê saída, pois a culpa pela ausência da leitura é anterior à escola.

\section{Narrativas de professores: artimanhas de leitura inventadas no cotidiano}

Para percebermos as práticas de leitura de professores, escolhemos um lócus e uma estratégia metodológica que acreditamos dar conta dos nossos objetivos que se centram na análise das práticas de leitura de professores. A escola escolhida deu-se por um critério alusivo ao habitus leitor, o nome da escola foi dado em homenagem a um jornalista piauiense apaixonado pela leitura, cuja sua biblioteca pessoal foi doada para acervos públicos. Como sujeitos desta pesquisa, temos seis professores de língua portuguesa da referida escola que aceitaram o convite para um diálogo sobre sua formação leitora e seus contatos atuais com a leitura.

Utilizamos como metodologia os aportes da história oral. Aquilo que se é leva-se uma vida inteira para construir. O registro do testemunho oral permite-nos um olhar sobre a história recriada por intermédio da reminiscência dos informantes, é uma sistematização que permite lançar luz sobre o tempo e sobre essa pluralidade de elementos que se entrelaçam durante uma vida inteira, vida esta que apreende a realidade e se dá pela representação que fazemos dela, onde a reflexão sobre a realidade é medida por valores, conceitos e aspirações que integram o acervo de nossa memória singularmente constituída no processo coletivo de nossa história.

Neste sentido a fala do indivíduo é um lugar privilegiado que permite o debruçar sobre percepções, experiências, considerando o caráter representativo de uma época, zelando pela experiência individual e lançando brechas para um viés objetivo na magnitude subjetiva. A pretensão é a sutileza do olhar, é a historicidade mesmo que na ingenuidade, é o escancarar da fala, é o olhar perdido do silêncio, é a busca na memória, é a lembrança do tempo ausente peça íngreme do presente, é arranjar as palavras que venham propiciar a outros um olhar 
plurissingular do passado ou lentes de aceitação e questionamentos de uma época permeada por ações, construções, representações e sentimentos.

Quando convidados a falar de suas experiências leitoras:

Vivemos uma cultura letrada, dependemos direta ou indiretamente dela. É interessante depois de leitores, pensar em como se deu esse processo, todos os professores deveriam fazer esse exercício, quem sabe assim eles entenderiam melhor a leitura, a leitura como um processo cultural e social (Fragmentos da fala de um dos informantes).

Em uma sociedade marcada pela cultura letrada, como evidenciamos no fragmento acima, estamos sem dúvidas a mercê de um grande legado, a leitura no presente precisa ser vista pelo passado, passado este tecido todos os dias como um elemento da memória em que, por conta dele, compreendemos o que fomos e como somos. Os indivíduos são produtores de História, assim, a história da leitura é produzida pelos leitores e também é produzida pelos que têm acesso a ela, pelos que a reconhecem e não tem acesso a ela e pelos que, mesmo tendo acesso, a recusam.

Ao pensar sobre o papel da família na constituição do habitus leitor, evidenciou um dos sujeitos da pesquisa: “A família tem um papel de destaque como instituição social se ela apoia reconhece o lugar da leitura e se ela não apoia dá margem pra reprodução da nãoleitura" (Fragmentos da fala de um dos informantes).

Identificamos neste fragmento que as situações sociais nas quais vivemos constituem verdadeiros "ativadores" de resumos de experiências incorporados, que são os nossos esquemas de ação ou nossos hábitos. Dependemos assim fortemente desses contextos sociais que tiram de nós certas experiências e deixam outras em estado de gestação. "Mudar de contexto é mudar as forças que agem sobre nós” (LAHIRE, 2002, p. 59). A família, sob esta lógica, ocupa lugar privilegiado na formação do habitus leitor.

Ao mencionar a escola enquanto lócus da formação leitora:

A escola é no mundo de hoje o espaço por excelência da formação leitora. São muitos anos neste espaço, até aqueles que não têm acesso a ela reconhecem isto. Outra coisa importante é o papel do professor e da sua prática pedagógica, geralmente o aluno se inspira muito na figura do professor (Fragmentos da fala de um dos informantes).

Nesta fala, a leitura dos atores sociais deve ser compreendida não apenas como operação intelectual, mas como uma relação de força simbólica, que se baseia numa relação de autoridade - crença necessariamente referida às condições dos discursos, mas precisamente à estrutura do mercado em que eles são referidos (BOURDIEU, 1987, p. 161). Desse modo, 
"a ciência dos discursos de levar em conta as condições de instauração da comunicação, porque as condições de produção. A produção é comandada pela estrutura do mercado" (BOURDIEU, 1987, p. 161-162).

É oportuno salientar ainda a ideia de que "os proponentes de estudos sociais terão que construir seus modelos pedagógicos sobre uma estrutura teórica que situe as escolas em um contexto sócio-político... estes proponentes terão que entender a escola como um agente de socialização" (GIROUX, 1997, p. 56).

Tal percepção de Giroux cabe aqui na intenção de apresentar a releitura do espaço escolar como visão macro para subsidiar a visão da pratica pedagógica, a qual não é uma mera concretização de receitas modelos didática ou esquemas conscientes de ação, é uma ação dirigida pelo habitus do professor que são esquemas de pensamentos, ação que alicerçam as inúmeras micro decisões tomadas na sala de aula (PERRENOUD, 1997).

Ao se referir ao capital cultural institucionalizado e sua relação com a leitura:

Os diplomas, as universidades, os cursos e as formações continuadas são importantes demais, quer queiramos ou não estes espaços nos obrigam a ler, afinal é uma condição pra estar ali. Só fico às vezes me perguntando se a oficialidade não faz agir mais por obrigação do que por prazer... Os cursos de formação da secretaria de educação, por exemplo, as pessoas fazem muito mais por obrigação do que pela necessidade de formação (Fragmentos da fala de um dos informantes).

Neste ponto, observamos o embate da legitimação da leitura como capital e as práticas simbólicas de sua apropriação. Quando da relação do capital cultural materializado e o acesso aos bens simbólicos:

O acesso à biblioteca é algo novo para as camadas populares... Os livros sempre desejei tê-los, mas dinheiro que é bom não tinha para adquiri-los ... O contato maior foi através da escola, que feliz é aquela que pode contar com um programa de distribuição de livro didático ou de incentivo a leitura, essas ações são extremamente importantes pra escola pública (Fragmentos da fala de um dos informantes).

Esta fala apresenta em seu bojo as discussões implícitas do capital cultural em relação ao acesso a bens simbólicos, ao capital econômico ao associar a aquisição ao dinheiro e ao capital social ao reconhecer a legitimidade da leitura enquanto bem simbólico.

E, finalizando, ao ser mencionado o gosto pela leitura podemos ter falas múltiplas:

"Gosto de ler, mas não tenho hábito de leitura" ou "Sinto algo diferente por ser leitor, faço questão de andar com livros para que me identifiquem como tal" ou "Ler, pra mim, é uma necessidade" ou "Para mim, ler alimenta a alma... mas tenho que estar inspirada não é toda hora" ou "A leitura é 
necessária para uma vida social e pra a participação na sociedade enquanto cidadão" ou "Ler é importante, mas não é tudo nesta vida" (Fragmentos das falas de todos os informantes).

Esta pluralidade de ditos evidencia o habitus leitor enquanto sistema de disposições, ações e percepções que os indivíduos adquirem com o tempo em suas experiências sociais, tanto na dimensão material, corpórea, simbólica quanto cultural. Assim, o agente que lê não busca apenas ser compreendido, mas ser obedecido, acreditado e reconhecido, daí a afirmação que: "a língua não é somente um instrumento de comunicação ou mesmo de conhecimento, mas um instrumento de poder" (BOURDIEU, 1987, p. 161).

\section{Considerações}

Os achados desta pesquisa apontaram para uma leitura de novas disposições do capital cultural, sinalizando a relação que é estabelecida entre a objetividade e a subjetividade dos professores pesquisados. Quando, através de suas trajetórias biográficas, os professores narram suas experiências com a leitura, pode-se observar o papel do ambiente escolar na formação do capital cultural institucionalizado, o papel do ambiente familiar que reconhece o hábito da leitura e o papel do ambiente familiar que incentiva esta prática como competência e como um valor simbólico.

Nas trajetórias dos professores é apontada a importância da escola pública que, assistida por programas de incentivo à leitura e distribuição de livro didático, dá um novo estímulo à formação leitora. Em consonância, todos os professores, ao relatarem suas experiências formativas, demonstraram que as exigências da cultura letrada impulsionam a necessidade da leitura, o que muitas vezes desloca a discussão do prazer de ler à obrigação de ler.

Destaca-se também, nas histórias de vida destes professores, as redes de socialização de leitores de uma mesma comunidade entendida como elemento estratégico na formação do habitus leitor. Tal observação fora detectada quando estes se referiam a estudo em grupo com colegas, com gostos e objetivos em comum no qual a seleção dar-se-á pelas afinidades.

Fora observada também esta rede de socialização, informações continuadas, aqui referidas a ações induzidas pelas políticas de formação do Estado, pois, em suas narrativas, os professores apontam esta dimensão de capital institucionalizado como tipo de capital em que você se apropria mais pelas exigências normativas do que pela iniciativa formativa. 
Um dos achados mais instigantes foi evidenciado em todas as entrevistas narrativas quando se pensou no livro como material impresso, cânone da representação leitora. No tocante à aquisição de livros, observou-se o desejo de tê-los, a dificuldade dos recursos para adquiri-los, a inacessibilidade das bibliotecas, as apropriações indevidas de acervos públicos, o culto ao livro como objeto e a sua exposição itinerária como demonstração simbólica do capital materializado.

Esta pesquisa abriu um leque que possibilitou uma multiplicidade de olhares sobre a leitura, a constituição do habitus e as novas disposições do capital cultural.

\section{REFERÊNCIAS}

ALBUQUERQUE, L. B. Natureza, sociedade e conhecimento: revistando os paradigmas. Educação e compromisso, Teresina, v. 5, n. 1 e 2, p. 233-234, jan./dez. 1992.

BOURDIEU, P. A distinção. São Paulo: Edusp, 2007.

BOURDIEU, P. A reprodução. Rio de Janeiro: Francisco Alves, 1975.

BOURDIEU, P. As regras da arte. São Paulo: Companhia das letras, 1996.

BOURDIEU, P. Coisas ditas. São Paulo: Brasiliense, 1990.

BOURDIEU, P. O poder simbólico. Trad. Fernando Tomáz. Rio de Janeiro: Bertrand Brasil, 1989.

BOURDIEU, P. Os três estados do capital cultural. In: NOGUEIRA, M. A.; CATANI, A. (org.). Escritos de educação. Petrópolis: Vozes, 1998.

CERTEAU, M. A invenção do cotidiano: artes de fazer. Petrópolis: Vozes, 2000. v. I.

CHARTIER, R. A história cultural: entre práticas e representações - memória e sociedade. Lisboa: Difel, 1990.

CHARTIER, R. Leituras e leitores e leitores na França do antigo regime. São Paulo: Editora UNESP, 2004.

CHARTIER, R. Práticas de leitura. São Paulo: Estação Liberdade, 1996.

GIROUX, H. A. Os professores como intelectuais: rumo a uma pedagogia crítica da aprendizagem. Porto Alegre: Artes Médicas, 1997

LAHIRE, B. Homem Plural. Os determinantes da ação. Trad. Jaime A. Clasen. Petrópolis, RJ: Vozes, 2002.

NÓVOA, A. Vidas de Professores. Porto: Porto Editora, 1992. 
ORTIZ, R. Pierre Bourdieu: Sociologia. São Paulo: Editora Ática, 1994.

PERRENOUD, P. Práticas Pedagógicas, profissão docente e formação perspectivas sociológicos. Portugal: Dom Quixote, 1993.

\section{Como referenciar este artigo:}

RIBEIRO GONDINHO, M. R.; OLIVEIRA, L. X. de; VELOSO, C. História da leitura: professores leitores, políticas de circulação do livro e as reverberações na docência. Rev. EntreLínguas, Araraquara, v. 6, n. 2, p. 436-448, jul./dez., 2020. e-ISSN: 2447-3529. DOI: https://doi.org/10.29051/el.v6i2.14294

Submetido em: 01/06/2020

Revisões requeridas: $20 / 08 / 2020$

Aprovado em: 25/07/2020

Publicado em: 30/09/2020 